\title{
PNEUMOCYSTIS PNEUMONIA ASSOCIATED WITH AGAMMAGLOBULINAEMIA
}

\author{
BY \\ J. G. B. RUSSELL \\ From the Royal Manchester Children's Hospital, Pendlebury
}

(RECEIVED FOR PUBLICATION JANUARY 27, 1959)

Infection with Pneumocystis carinii causes an interstitial cell pneumonia. It has been rarely reported in this country since Baar recorded a case in 1955.

The case reported here is of interest in that such an infection was associated with agammaglobulinaemia in a female infant.

\section{Case Report}

C.O., a female infant, had a birth weight of $6 \mathrm{lb}$. (2,720 g.). The parents were English and had one other normal child.

She was admitted to hospital at the age of 3 days because of abdominal distension and vomiting. This settled without specific treatment. She went home but was readmitted two weeks later with similar symptoms together with loose stools. Intravenous fluids were required and E. coli 026 was isolated from the stool. She was treated with neomycin, recovered and went home for two weeks before being readmitted again, dehydrated with diarrhoea and vomiting, and with abdominal distension. Following a course of tetracycline, she made satisfactory progress, gaining $2 \frac{1}{2} \mathrm{lb}$. $(1,100 \mathrm{~g}$. $)$ in a month, reaching $9 \frac{1}{2} \mathrm{lb}$. $(4,100 \mathrm{~g}$.), but then had another attack of loose stools with gross abdominal distension. She was now aged 3 months and respiratory distress was noticed for the first time and was thought to be caused by the abdominal distension. A radiographic examination using a barium meal showed a distended colon, a rectum of normal calibre and coning in the rectosigmoid area. A diagnosis was made of Hirschsprung's disease, associated with enteritis. She failed to thrive.

She was transferred to the Royal Manchester Children's Hospital at the age of $5 \frac{1}{2}$ months. She then still weighed $9 \frac{1}{2} \mathrm{lb}$. There was gross abdominal distension with an empty rectum and she had a respiratory rate of 90 per minute associated with a bronchopneumonia. She was having loose offensive stools and vomiting. E. coli 026 was again isolated from the stool.

Tetracycline was given and she slowly improved. The E. coli 026 disappeared and 10 days after admission a laparotomy was carried out. The colon was dilated and appeared to cone to normal size at the pelvi-rectal junction. Biopsies were taken above and below this site and a colostomy carried out proximal to it. However, post-operatively the distension persisted; and as normal nerve plexuses were found in the biopsies, the diagnosis of Hirschsprung's disease was not confirmed.

She had continuous loose stools and vomiting, and required frequent intravenous fluids, including blood and plasma. An antibiotic resistant Proteus morgani was continually found in the faeces. From this time until her death the respiratory rate was rarely below 50 per minute and for several periods when she had signs of a bronchopneumonia was around 70 per minute. In between these exacerbations in the lungs there were persistent scattered crepitations, mainly at the bases. Radiographs taken at this time between attacks of bronchopneumonia were reported as normal. In retrospect, however, the lung fields do appear a little hazy. Because of the diarrhoea, large doses of potassium were given to maintain blood levels at a satisfactory value. She developed a bilateral otitis media, which did not respond to courses of erythromycin, novobiocin or streptomycin. The white cell count reached 12,000 per c.mm. with a polymorphic preponderance. The eosinophils were often absent and never rose above 130 per c.mm.

At this time, at the age of 7 months, the plasma proteins were examined by paper electrophoresis. It was found that the gamma globulin was only just detectable, although she had received blood and plasma before the estimation. The isohaemagglutinins were also reduced. The parents had a normal plasma electrophoretic pattern.

In view of her critical condition, it was decided to institute gamma globulin therapy without delay. She was given $0.5 \mathrm{~g}$. of gamma globulin i.m. and $0.25 \mathrm{~g}$. bi-weekly together with further blood transfusions. It was calculated that this would produce a level near the normal. This therapy had no apparent effect on her continuing diarrhoea and otitis media. Two weeks later a course of cortisone $5 \mathrm{mg}$. t.d.s. was given for three weeks, with novobiocin and streptomycin. Again the response was disappointing. She was given a short course of A.C.T.H. A week later she died at the age of 8 months. The immediate cause of death was a recrudescence of bronchopneumonia. 
Autopsy (Dr. H. B. Marsden). Weight at death was $9 \mathrm{lb} .12 \mathrm{oz}$. (4,200 g.), and length $16 \frac{1}{2} \mathrm{in}$. $(41 \cdot 5 \mathrm{~cm}$.). She was a wasted child with marked abdominal distension. There was a left-sided colostomy.

The main findings were in the lungs. Weights: left lung $96 \mathrm{~g}$. (normal $45 \mathrm{~g}$.), right lung $118 \mathrm{~g}$. (52 g.). The lungs were red-brown, solid throughout, with dilated bronchi containing pus. Microscopically there was extensive pneumonitis with acute and chronic inflammatory cells and plugs of exudate in the bronchial channels. The alveolar septa were thickened. Oedema, fibrin and haemorrhage with, in addition, foamy vacuolated material with swollen macrophages were seen in the alveoli (Fig. 1). Some of the vacuolated material could thoracic and cervical regions. Microscopically, they showed an absence of plasma cells.

\section{Comment}

The diagnosis of agammaglobulinaemia was not finally confirmed before death in this case as it was felt that withholding treatment would seriously prejudice the baby's chances of survival. However, the diagnosis appeared to be confirmed by the absence of plasma cells in the necropsy material, which is the picture found in agammaglobulinaemia. This seems to be a true case of congenital agammaglobulinaemia because of the early onset of

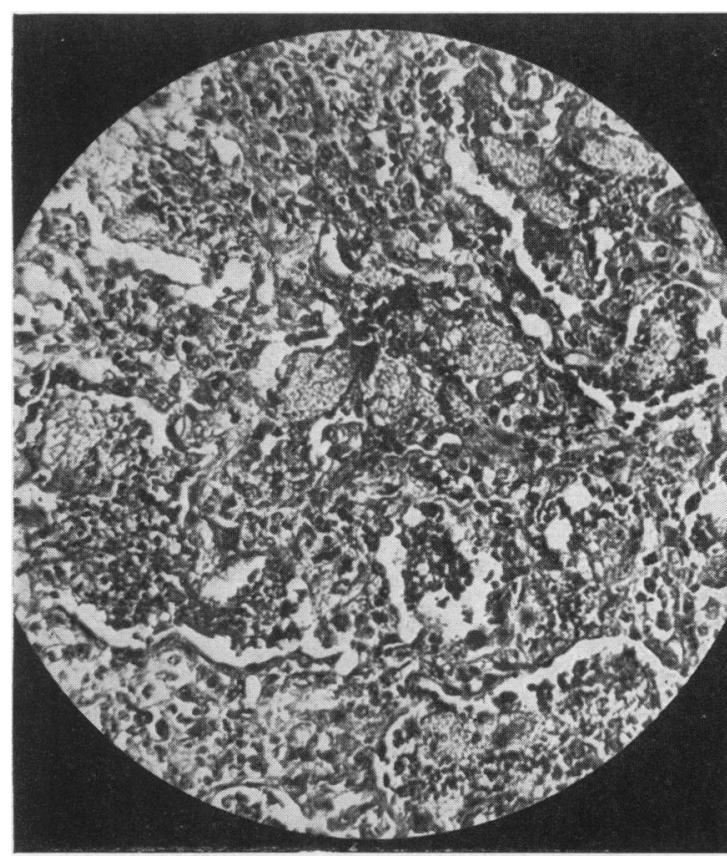

(a)

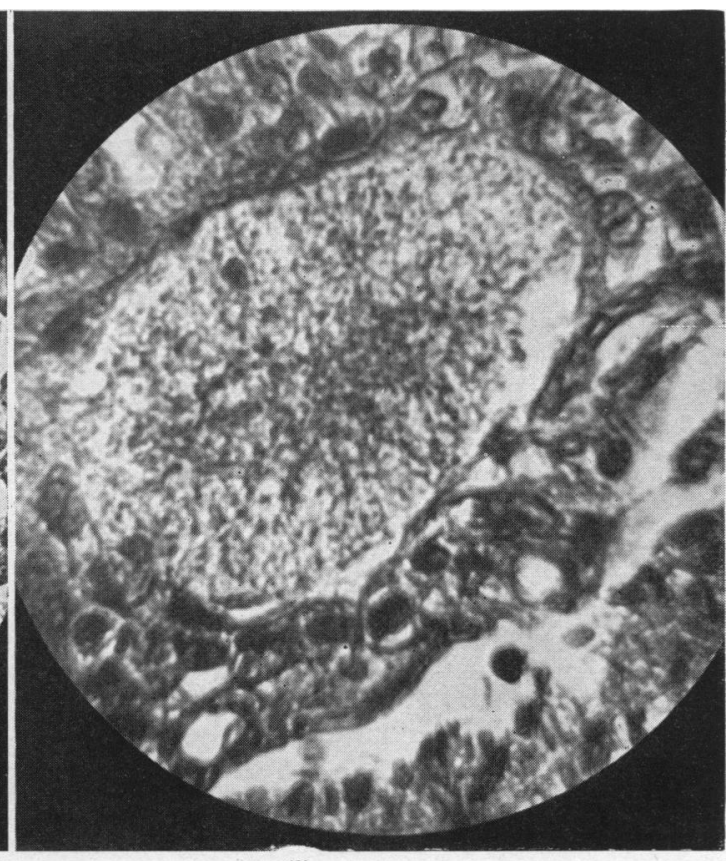

(b)

Fig. 1.-Sections of lung, showing the foamy material lying in the alveoli, which was found to contain the Pneumocystis on silver staining (a) $\times 75$. (b) $\times 650$. Stain $\mathrm{H}$. and $\mathrm{E}$.

have been due to aspiration, but in parts there was a resemblance to Pneumocystis infection. There was a possible preponderance of reticulum cells. No plasma cells were seen. Silver impregnation (Le Tan Vinh, 1954) showed the presence of Pneumocystis carinii.

The large intestine was distended up to $4 \mathrm{~cm}$. in diameter. It contained yellow liquid material and had a pale mucosa. Microscopically, the nerve supply was normal thus finally disproving the diagnosis of Hirschsprung's disease.

The reproductive organs were normal, confirming the female sex.

The only other relevant findings were in the lymph nodes. There were moderately sized nodes in the mesentery, and rather large red-black nodes in the symptoms. In fact, the first attacks of enteritis occurred whilst the gamma globulin level in the child must have been near to that of the mother. The newborn's gamma globulin is maternally and perhaps placentally derived, and is as high as or higher than that of the mother. Yeivin, Salzberger and Olitzki (1956) have, however, shown that the antibodies of the enteric group, including $E$. coli, are present in much lower concentration in the newborn than in the mother's serum. Thus the newborn child is liable to attacks of enteritis, but the recurrent attacks in our patient due to the same organism are perhaps significant. 
It is difficult to distinguish a true case of congenital primary agammaglobulinaemia from those cases in which there is an exaggeration of the physiological fall which occurs in the gamma globulin in infancy. Even in true agammaglobulinaemia, traces of gamma globulin can usually be detected. The true congenital form does not appear to have been previously reported in females. Harris and Schick (1954) gave unstated amounts of gamma globulin to female infants with antibiotic-resistant infections with good results, but made no measurement of the gamma globulin level. Pearce and Perinpanayagam (1957) reported the case of a female found to have agammaglobulinaemia from the age of 3 years. It was thought to be congenital because she had had recurrent infections from the age of 8 months. She had also an enlarged spleen and lymph nodes, which are common in the acquired form, and it seems likely that this was the acquired form starting at an unusually early age (Lancet, 1958). The diagnosis of agammaglobulinaemia was delayed in our case because it was thought not to occur in female infants.

Pneumocystis carinii is an aetiological agent of interstitial cell pneumonia. Infection with it has been reported in England only by Baar in 1955 . Four cases have been reported from Scotland (Hutchinson, 1955; Bird and Thomson, 1957). Gerrard and Moore (1957) reported two similar cases from Canada. In each of these two latter reports agammaglobulinaemia in two boys was found to be associated with pulmonary Pneumocystis infection, and in each case a brother had also died of Pneumocystis infection. It seems reasonable to suppose that these siblings had also agammaglobulinaemia.

There are many cases reported from the Continent not associated with agammaglobulinaemia. Von Harnack (1954) was able to report 191 cases seen in Hamburg in four years, and there were over 700 cases in Switzerland in 1941-8 (Freudenberg and Tobler, 1950). It occurs in the first year of life, usually in infants who are premature, but less commonly also in debilitated older children. Rarely cases are reported in adults, generally with diseases of the reticulo-endothelial system. The incubation period is one to two months. There is an insidious onset of increasing dyspnoea. Physical signs are strikingly few in comparison with the marked respiratory distress, perhaps a few small patches of bronchial breathing, and a few coarse crepitations in some areas. Fever is absent or low grade. The mortality of diagnosed cases is about $20 \%$, but probably many mild cases are not diagnosed. Radiographically, a diffuse ground glass appearance is generally found (Gajdusek, 1957). The hilar nodes are not enlarged. However, the picture appears to vary widely. In our patient, in between attacks of bronchopneumonia, the chest film showed little or no abnormality. Bird and Thomson (1957) noted fluffy opacities which became widespread and confluent. It may have been that the infection in our case was a terminal event as it apparently was in Hutchinson's first case, where the disease only lasted three days, but it seems more likely that it was responsible for the continuous dyspnoea which continued over the last four and a half months of her life.

The pulmonary infection was probably responsible for the continuous diarrhoea and abdominal distension, on which clinical attention was focused during the last months of her life. Whilst usually the presenting feature of Pneumocystis infection is dyspnoea, Hutchinson's second case also presented with vomiting, diarrhoea and loss of weight.

Histologically, in the lung there is extensive mononuclear infiltration of the septa. The alveoli are filled with exudate which, on high magnification, can be seen to be composed of masses of the parasite. If there is an associated agammaglobulinaemia the picture is modified in the absence of plasma cells. The organism, Pneumocystis carinii, has been classed as a protozoon, although some believe it to be a yeast.

Treatment has, until recently, been symptomatic, humid oxygen being the most effective agent. Tube feeding may be needed if the dyspnoea is severe. Antibiotics should be given as the diagnosis cannot be finally made on clinical examination, and in many cases there is an associated bacterial pneumonia. Antibiotics have no effect on the Pneumocystis. Gamma globulin has no effect even when there is an agammaglobulinaemia. It did not help our case, neither did it in Bird and Thomson's second one. Large doses of gamma globulin in this latter case did not affect the electrophoretic pattern of the serum proteins. Cortisone and corticotrophins are without effect. Recently success has been reported (Ivády and Páldy, 1958) using quinquivalent antimony compounds and aromatic diamidines.

The diagnosis of Pneumocystis infection is thus no longer of academic interest. Antibodies are formed and a complement fixation test has been developed (Haneke and Roser, 1958). There have been no reports of the organism being found in the sputum, but it seems reasonable to look. The white cell count shows an increase, with a polymorphic response, and an eosinophilia is often present. Gellis (1958) advocates lung puncture to confirm the diagnosis. The disease should always 
be suspected in a patient with an antibiotic-resistant pneumonia, or in one who has dyspnoea, especially if the physical signs are few. It may, however, present through the gastro-intestinal system.

\section{Summary}

A patient with Pneumocystis carinii pneumonia is described in whom there was associated agammaglobulinaemia. This latter seemed to be congenital in origin, and is unusual in that it occurred in a female infant.

My thanks are due to Mr. A. Jolleys, under whose care the patient was, for permission to publish, and to Dr. H. B. Marsden for the necropsy report, and to both for their criticism.

\section{REFERENCES}

Baar, H. S. (1955). J. clin. Path.; 8, 19.

Bird, T. and Thomson, J. (1957). Lancet, 1, 59.

Freudenberg, E. and Tobler, W. (1950). Ann. paediat. (Basel), 175, 185.

Gajdusek, D. C. (1957). Pediatrics, 19, 543.

Gellis, S. S. (1958). Year Book of Pediatrics, 1958-59 series, p. 243. Chicago.

Gerrard, J. W. and Moore, D. F. (1957). Canad. med. Ass. J., 76, 299 .

Haneke, K. and Roser, F. (1958). Kinderärztl. Prax., 26, 63.

Harnack, G. A. von (1954) Ann. paediat. (Basel), 183, 224.

Harris, J. R. and Schick, B. (1954). J. Mt Sinai Hosp., 21, 148.

Hutchinson, J. H. (1955). Lancet, 2, 844, 1196.

Ivády, G. and Páldy, L. (1958). Mschr. Kinderheilk., 106, 10

Leading article (1958). Lancet, 1, 1317.

Le Tan Vinh (1954). Arch. franc. Pediat., 11, 1035.

Pearce, K. M. and Perinpanayagam, M. S. (1957). Arch. Dis. Childh., 32, 422.

Yeivin, R., Salzberger, M. and Olitzki, A. L. (1956). Pediatrics, 18, 19 . 